\title{
ALTERAÇÕES NO PESO FETAL, FÍGADO, PLACENTA E CORDÃO UMBILICAL DE RATAS INDUZIDAS PELA ADMINISTRAÇÃO DE GENTAMICINA DURANTE A PRENHEZ
}

\author{
Stella Maris S. DUARTE ${ }^{1}$ \\ Thatiana Cristina Vieira de REZENDE² \\ Andrea A. SANTOS 2 \\ Maria Rita RODRIGUES ${ }^{2}$ \\ Tomaz H. ARAÚJO²
}

Universidade Federal de Alfenas - MG. Rua Gabriel Monteiro da Silva, 714. CEP:37130-000 Alfenas - MG Brasil.

1 Faculdade de Farmácia - Universidade Federal de Alfenas-MG;

2 Instituto de Ciências Biomédicas - Universidade Federal de Alfenas - MG.

Recebido em: 30/05/2014 - Aprovado em: 25/09/2014 - Disponibilizado em: 15/12/2014

\begin{abstract}
RESUMO
O propósito do presente trabalho é verificar a ação da gentamicina, antibiótico do grupo dos aminoglicosídeos, no feto e as alterações induzidas no fígado, placenta e cordão umbilical.Foram utilizadas ratas albinas, variedade Wistar, que receberam dose única de gentamicina $5 \mathrm{mg} / \mathrm{Kg}$ de peso corporal, por injeção intramuscular, no $10^{\circ}$ dia de prenhez. No $20^{\circ}$ dia os animais foram sacrificados. Notou-se retardo no crescimento intra-uterino. A gentamicina reduziu significativamente o peso do feto e da placenta e o comprimento do cordão umbilical. O fígado fetal apresentou aumento significativo do tecido conjuntivo intersticial, desorganização das placas de hepatócitos e dos capilares sinusóides. Os hepatócitos mostraram o citoplasma bastante vacuolizado. A análise dos resultados leva a conclusão de que a gentamicina na dose administrada não causou nenhuma má formação, mas induziu alterações no fígado, peso fetal, placenta e cordão umbilical, quando administrados durante a prenhez.
\end{abstract}

Palavra Chave: Cordão umbilical. Fígado. Gentamicina. Prenhez. Peso fetal.

\section{SUMMARY}

Aminoglycosides are antibiotics used in the treatment of infections caused by gram-negative bacteria. They cross the placenta, are ototoxic in children and are nephrotoxic in adults. The exposure to such antibiotics must be careful during fetal development. So, the purpose of this study was to verify their action in fetus and evaluate, morphologically and morphometrically, the changes they induce in the fetal liver, placental and umbilical cord. Albino Wistar rats received a single intramuscular dose of 5 milligrams of gentamicin on the tenth day of pregnancy. The rats were sacrificed on the $20^{\text {th }}$ day. A delay in intra-uterine growth was macroscopically observed. Gentamicin significantly reduced the fetal weight, the placental weight and the length of umbilical cord. Histologically, the gentamicin-treated animals exhibited livers with disorganized hepatocyte plaques and capillary sinusoids. The hepatocytes showed a very vacuolated cytoplasm. Not withstanding the increased interstitial connective tissue. It was concluded that the doses of gentamicin used in this study caused no malformation, but induced changes in the fetal liver when administered during pregnancy. Keywords: Fetal liver. Pregnancy. Placenta. Gentamicin.. Umbilical cord.

\section{INTRODUÇÃOO}

A gentamicina é um fármaco de complexa estrutura química, da classe dos antibióticos de largo espectro (LOURENÇO, 2009), isolada de um actinomiceto (Micromonospora purpúrea) usada basicamente no tratamento de infecções por bactérias aeróbias gramnegativas, inibindo a síntese proteica destas. Trata-se de aminoglicosídeo de baixo custo e de atividade confiável. Em virtude de sua natureza polar, a gentamicina é muito mal absorvida pela via gastrointestinal, portanto 
sua administração deve ser realizada por via intravenosa, intramuscular ou tópica. Sua ligação à albumina plasmática é pequena, tendo pouca lipossolubilidade, o que induz a uma baixa concentração nas secreções e nos tecidos. Somente são encontradas concentrações elevadas no córtex renal e na endolinfa e perilinfa do ouvido interno. É possível que isto contribua para a nefrotoxicidade e para ototoxicidade causada por este fármaco, o que limita o seu uso. (H.P.RANG...et all,2007).

Os aminoglicosídeos são capazes de atravessar a placenta por isto sua administração às gestantes pode resultar no acúmulo deste fármaco no plasma fetal e líquido amniótico. (SMAOUI, 1993)

YOSHIOKA et al. (1972) demonstrou que 1 hora após a administração intramuscular de gentamicina, o pico do fármaco no cordão umbilical chega a 34,2\% do nível materno. FIOL (2005) confirmou que a gentamicina é o fármaco do grupo mais utilizado durante a gestação, com indicação para pielonefrites que não respondem aos tratamentos utilizando agentes beta-lactâmicos Sua eliminação é feita quase totalmente pelo rim, sendo filtrada no rim adulto e reabsorvida pelas membranas apicais das células do túbulo proximal, onde é incorporada aos lisossomas ou excretada pela urina (SILVERBLATT \& KUEHN, 1979). Trabalhos utilizando cobaias mostraram que os rins de fetos e rins de adultos são os maiores sítios de deposição de gentamicina, seguido pelo fígado e pulmões (LÉLIEVREPÉGORIER et al., 1985).

WILFERT (1971) demonstrou que o fármaco se mostra nefrotóxico em adultos humanos por até 10 dias após o início da terapia e o primeiro sinal clínico é o aumento da creatinina plasmática. Além disso, o retorno às funções renais normais ocorre somente após mais de cinco meses do término de uso do medicamento (KOSEK et al.,1974).

CAMPOS (1998) estudou em fetos de ratos as alterações induzidas na cavidade oral pela administração de gentamicina durante a prenhez, observando que o epitélio de revestimento da língua torna-se mais espesso, com a camada de queratina mais delgada. As glândulas linguais mostraram-se mais imaturas com núcleos mais volumosos e as fibras musculares esqueléticas com núcleos maiores.

Posteriormente, SILVA (1999), evidenciou que a gentamicina administrada durante a prenhez provoca no feto o aparecimento de fibras musculares cardíacas mais estreitas, com núcleos de menor volume e acentuada miocitólise.

Em 1994 SANFORD et al. alertou que os dados disponíveis sobre a ação destes antibióticos no feto eram insuficientes, recomendando que fossem utilizados com cautela na gravidez. Um levantamento bibliográfico atual nos mostrou que ainda continuam insuficientes as informações sobre a ação deste antibiótico na gravidez. Assim, o 
objetivo deste trabalho é avaliar a ação da gentamicina no peso do feto, no fígado fetal e no cordão umbilical e placenta.

\section{MATERIAL E MÉTODOS}

Para a realização deste estudo foram utilizadas seis ratas albinas (Rattus norvegicus, variedade Wistar), cujo peso variou de $220 \mathrm{~g}$ a $250 \mathrm{~g}$. As ratas foram tratadas com ração comercial e água "ad libitum”.

Com a finalidade de determinar com precisão o $1^{\circ}$ dia da prenhez das ratas, estas foram acasaladas com os machos durante a noite e, pela manhã, feitos esfregaços vaginais visando verificar a presença de espermatozoides. Quando isso ocorreu, esse dia foi considerado como o primeiro dia de prenhez. As ratas foram alojadas em gaiolas individuais.

No $10^{\circ}$ dia de prenhez foi administrada gentamicina (Garamicina injetável Schering-Plough) na dose única de $5 \mathrm{mg} / \mathrm{kg}$ de peso corporal por via intramuscular, em três ratas. Os outros três animais serviram de controle e receberam solução salina.

No $20^{\circ}$ dia de prenhez as ratas foram sacrificadas por inalação de gás carbônico e através de uma incisão foram colhidos os fetos, sendo obtidos 5 fetos das 3 ratas que receberam gentamicina; e outros 5 fetos das 3 ratas que receberam solução salina. Aprovado pelo Comitê de Ética em Pesquisa Animal.
O material foi fixado em paraformaldeido $4 \%$ por 12 horas. Todos os fetos, placentas e cordões umbilicais, após a fixação, foram secos em papel de filtro e pesados. Uma vez pesados, os fetos, placentas e cordões umbilicais foram lavados e imersos em álcool a $80 \%$.

Amostras dos fígados dos fetos foram incluídas em parafina e cortes seriados de sete micrômetros foram corados pela hematoxilina - eosina e analisados e fotografados em microscópio Axiophot Zeiss.

\section{RESULTADOS}

O fígado dos fetos do grupo controle apresentou aspecto típico, com células hepáticas agrupadas em placas interconectadas com orientação radial e separadas entre si por tecido conjuntivo. Nos espaços entre as placas celulares de hepatócitos foram encontrados sinusoides e uma grande quantidade de células precursoras e maduras do sangue. Também foram observados muitos megacariocitos e células de Kupffer. (fig.1,2) 
Figura 1- Aspecto geral do figado dos fetos de ratos controle.Observa-se grande numero de células precursoras dos elementos figurados do sangue.H.E.Barra $2 \mu \mathrm{m}$.

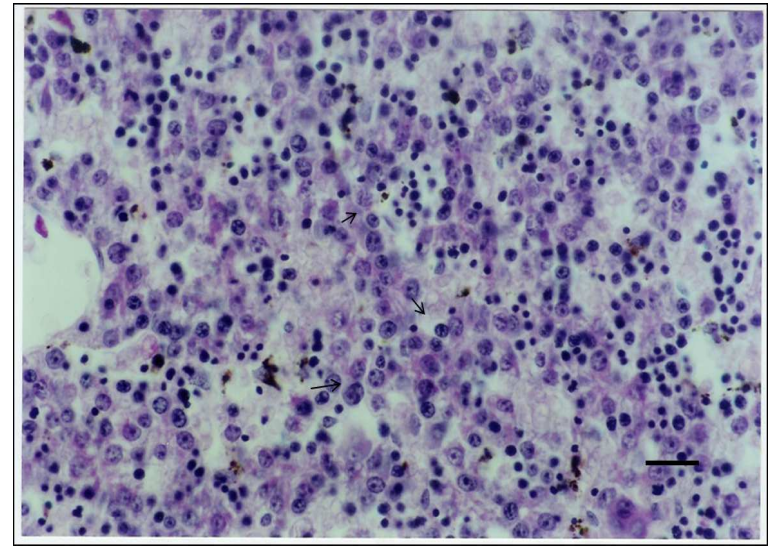

Figura 2 - Feto Controle. Aspecto geral do fígado. Observa-se megacariocito (seta) no parênquima hepático. $\quad$ H.E.Barra $\quad 2 \quad \mu \mathrm{m}$.

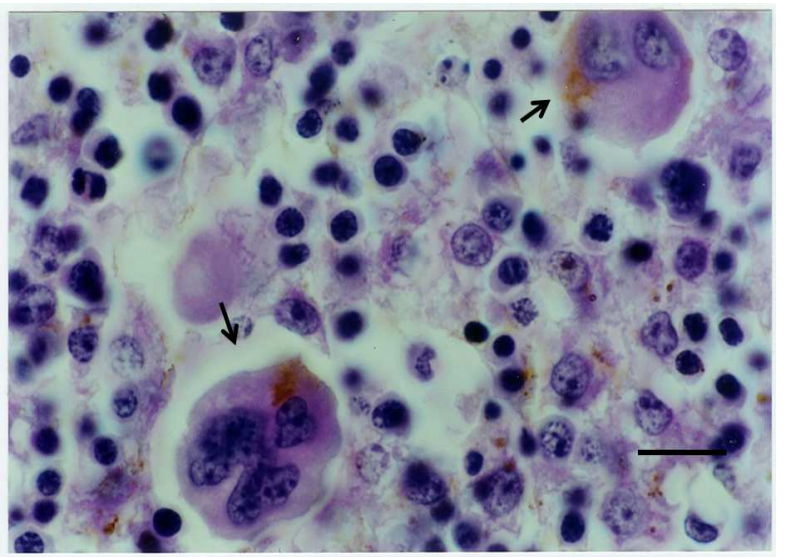

Nos fetos tratados com gentamicina o fígado apresentou os hepatócitos desorganizados, sem o arranjo típico de placas interconectadas, com uma maior quantidade de tecido conjuntivo, porém com menor número de células precursoras do sangue, inclusive megacariócitos. Os hepatócitos apresentaram o citoplasma bastante vacuolizado. Os capilares sinusóides nesses animais também se mostraram mais desorganizados. (fig.3).
Figura 3 - Feto Tratado. Aspecto geral do fígado. Megacariócitos entre o parênquima hepático desorganizado. H.E

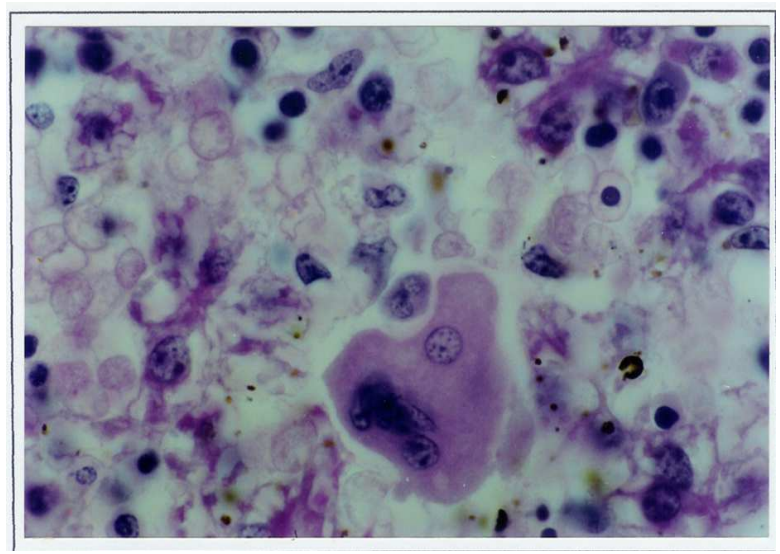

Os pesos corporais médios dos fetos foram de 5,18 gramas para o grupo controle e 3,56 gramas para o grupo tratado com gentamicina. O teste Mann-Whitney mostrou diferença estatisticamente significante entre os grupos controle e tratados $(\square=0,01)$.

O peso médio da placenta foi de 577,18 miligramas para o grupo controle e 342,52 miligramas para o grupo tratado com gentamicina. $O$ teste de Mann-Whitney acusou diferença estatisticamente significante ( $\square=0,01)$ entre os grupos.

O comprimento médio do cordão umbilical dos fetos foi de 2,32 centímetros para o grupo controle e 2,04 para o grupo tratado com gentamicina. $O$ teste de Mann-Whitney acusou diferença estatisticamente significante entre os grupos estudados ( $\square=0,01)$.

\section{DISCUSSÃO}

Sabe-se que a placenta desempenha um papel central na regulação do crescimento fetal. Assim, o crescimento do feto é influenciado 
essencialmente pelo peso e valor funcional da placenta. Isto explica por que nos gêmeos bivitelinos o recém-nascido $(\mathrm{RN})$ de maior peso corresponde à placenta de maior peso ( Kloos e Vogel, 1978).

O peso da placenta, tal como o peso do RN, é influenciado por vários fatores maternos, como a nutrição, infecções, diabetes mellitus, hipertensão, anemia, altitude, hipóxia aguda, infarto, malformações congênitas, paridade, lupus eritematoso sistêmico e sindromes genéticas (Stoll e cl 1990).

Placentas pequenas estão associadas a menores valores de permeabilidade placentária por quilograma de peso fetal. A capacidade do feto para crescer e amadurecer no útero presume-se então estar relacionada com a habilidade da placenta em oferecer nutrientes. Recém-nascidos ligados a uma placenta pequena apresentam maior incidência de sofrimento fetal. Isto por que a redução do tecido funcional da placenta é acompanhada pela diminuição da área de troca entre a mãe e o feto, tanto na área da superfície vilosa como na área da superfície capilar fetal (Yu,1992). Assim, uma pequena placenta pode representar deficiências na habilidade de transferir oxigênio e nutrientes da mãe ao feto e causar alterações no crescimento e desenvolvimento intrauterino. Um feto ligado a uma pequena placenta tende a ser menor quando comparado a um feto ligado a uma placenta normal de mesma idade gestacional
Em nosso trabalho o peso da placenta das ratas tratadas foi menor que o peso da placenta das ratas controle, sugerindo que a gentamicina usada durante a gestação pode ser prejudicial.

Nossos resultados também sugerem que a ação da gentamicina, diminuindo o tamanho da placenta, tem consequências no peso do feto, o que está de acordo com os achados de CAMPOS, 1998; e SILVA, 1999 e tem considerável importância clinica.

MOESSINGER (1983) sugeriu que o cordão umbilical seria um indicador confiável do movimento fetal e que o comprimento do cordão umbilical é influenciado por, pelo menos, dois fatores: a incidência do movimento fetal e o espaço intra-uterino disponível. A redução do espaço intra-uterino ou do movimento fetal implica em uma diminuição do estiramento do cordão umbilical com consequente encurtamento do mesmo. Injetando curare em roedores durante a prenhez, com a finalidade de aumentar a pressão do saco amniótico e suprimir os movimentos fetais, MOESSINGER (1983) observou cordões umbilicais mais curtos.

Cordões umbilicais encurtados também foram observados em humanos com defeitos estruturais dos membros, isto por que os defeitos dos membros limitam o movimento fetal (MILLER et al., 1981). Cordões umbilicais mais curtos são observados em ratos que recebem dosagens altas de vitamina A durante a prenhez, expostas á ação do 
metilmercúrio, submetidas à restrição protéica , submetidas à hipertermia, e também sob a ação da ciclofosfamida e de metais pesados como o chumbo (KOMESU et al., 1995).

BARRON et al. (1986), observaram movimentos fetais suprimidos e cordões umbilicais mais curtos naquelas ratas prenhas expostas à ação do álcool. A esses mesmos resultados chegou OLIVEIRA (1994) quando injetou etanol e aguardente de cana em ratas durante a prenhez.

Em nossos estudos os animais tratados com gentamicina revelaram cordões umbilicais mais curtos, o que indicaria limitação do movimento fetal já que os outros fatores conhecidos (hipervitaminose A, metilmercurio, restrição protéica, hipertemia, ciclofosfamida e chumbo) não estavam presentes neste modelo experimental. É também importante reconhecer que não existe correlação entre o comprimento do cordão umbilical com a idade, peso e altura da mãe, pré-eclâmpsia, ou com o modo de apresentação da criança (sexo, peso ou comprimento corporal), ou ainda com o peso da placenta ou o peso da criança ao nascer (WALKER, 1968).

Quanto ao tecido hepático, em nosso trabalho o fígado dos fetos cujas mães foram tratadas com gentamicina, apresentou uma desorganização das placas de hepatócitos, com aumento do espaço intersticial entre as células, e também desorganização do sistema de canais vasculares constituídos pelos capilares sinusóides. O citoplasma dos hepatócitos mostrou-se bastante vacuolizado, indicativo de degeneração celular. Nos fetos de ratas tratadas com gentamicina também ocorreu redução, no fígado, das células precursoras dos elementos celulares do sangue, quando comparado aos fetos de ratas controle, o que sugere uma pancitopenia periférica que poderia resultar em anemia, granulocitopenia e trombocitopenia. Então, percebemos que a gentamicina atua diretamente nos tecidos fetais, e, de acordo com (FIOL, 2005), a gentamicina atravessa livremente a placenta com picos de concentração fetal em torno de $40 \%$ da concentração materna, uma a duas horas após uma administração. Tal fato recebe apoio no trabalho de LÈVIEVRE-PÉGORIER et al. (1985) quando, injetando gentamicina durante a prenhez da cobaia, verificaram sua presença no plasma fetal, como também nos rins, fígado, pulmão, coração e cérebro em desenvolvimento.

\section{CONCLUSÕES}

A análise dos resultados obtidos permitiram concluir que a dose de 5 miligramas de gentamicina por quilograma de peso corporal aplicada intramuscular em rata no $10^{\circ}$ dia de prenhez provoca no feto:

a) Diminuição dos pesos corporais dos animais tratados quando comparados com os animais controles; 
b) Diminuição do peso da placenta nos animais tratados quando comparado com os animais controles;

c) Diminuição no comprimento do cordão umbilical nos animais tratados indicando movimento fetal diminuído;

\section{REFERÊNCIAS BIBLIOGRÁFICAS}

BARRON, S.; RILEY, E.P.;

SMOTHERMAN, W.P. The effect of prenatal alcohol exposure on umbilical cord length in fetal rats. Alcoholism clinical in the experimental research, Baltimore, 1986,v. 10, n. 5, p. 493-495.

CAMPOS, A. A. Estudo morfométrico e estereológico das alterações presentes nos epitélios de revestimento e glandular, e no músculo da língua de fetos de ratos, induzidas pela administração de gentamicina durante a prenhez. Dissertação (mestrado). Faculdade de Odontologia de Ribeirão Preto da Universidade de São Paulo, 1988.

COSTA, J.R.V. Hipervitaminose A em fetos de ratos. I. estudo morfológico, morfométrico e estereológico das alterações presentes no epitélio da mucosa palatina. II. Estudo da relação dose/efeito. Tese (titular) Escola de Farmácia e Odontologia de Alfenas, 1988.

F. S. D. FIOL, M. GERENUTT; F. C. d) fígado com placas de hepatócitos com citoplasmas bastante vacuolizados e capilares sinusóides desorganizados, com um aumento do tecido conjuntivo intersticial, porém, com menor número de precursores hematopoiéticos inclusive de megacariócitos.

gestação. Antimicrobial therapy during pregnancy. 2005,pags 111-114

KOSEK, J.C., MAZZE, R.I., COUSINS, M.J. Nephrotoxicity of gentamicin. Laboratory Investigation, 1974, v. 30, n.1, p. 48-57.

\section{LÈLIEVRE-PÉGORIER, M.; EUZET, S.;} MERLET-BÉNICHOU, C. Effect of fetal exposure to gentamicin on phosphate transport in young rat kidney. American Journal of Physiology, 1993, v. 265, p. 807812 .

\section{LÈLIEVRE-PÉGORIER, M.; SAKLY, R.;} MEULEMANS, A.; MERLEYT

BÉBICHOU, C. Kinetics of gentamicin in plasma of non pregnant, and fetal guinea-pigs and its distribution in fetal tissues. Antimicrobial Agents Chemotherapy, 1985, v. 28, n. 4 , p. 565-569.

MILLER, M.E; HIGGINBTTON, M.; SMITH, D.W. Short umbilical cord: its origin

Groppo; Terapêutica antimicrobiana durante a 
and relevance. Pediatrics, Evanston, 1981, v. 67, n.5, p. 618-621.

MOESSINGER, A.C. Fetal akinesia

deformation sequence: an animal model.

Pediatrics, Evanston, 1983, v.72, n.6, p. 857863.

OLIVEIRA, P.T., et al. I. The effect of hyperthemia on umbilical cord and placenta. Anais de Farmácia e Química, São Paulo, 1993-1994, v. 33-34, supl., p .91, 1993-1994.

SANFORD, J.P., et al. The Sanford guide to antimicrobial therapy. Antimicrobial Therapy Inc., Dallas, 1994, v. 7, p. 104.

\section{SCHAEVERBEKE H SMAOUI, J P}

MALLIE, M SCHAEVERBEKE, Gentamicin administered during gestation alters glomerular basement membrane 1993,119 10.1128/AAC.37.7.1510., A Robert and J development Antimicrob. Agents Chemother 37(7):1510. DOI:

SILVA, A.C. Estudo morfométrico e morfológico das alterações presentes no coração de fetos de ratos, induzidas pela administração de gentamicina durante a prenhez. Dissertação (Mestre). Escola de Farmácia e Odontologia de Alfenas, 1999.

\section{SILVERBLATT, F.J.; KUEHN, C.}

Autoradiography of gentamicin uptake by the rat proximal tubule cell. Kidney International, 1979, v.15, n.4, p. 335-345.

SMAOUI, HATEM. Transplacental effects of gentamicin on endocytosis in rat renal proximal tubule cells.Peditric nephrology, v. 8 , fasc. 4 , pag. $447-450$

WALKER, C.W.; PYE, B.G. The length oh human umbilical cord. Statistical Report of British Medical Journal, London,1968, v. 57, p. 621.

WEINSTEIN, M.J., et al. Gentamicin, a new antibiotic complex from Microminospora, Journal od Medicine and Chemistry,1963, v. 6, p. 463-364.

WYNN, R. L. Gentamycin for prophylaxix of bacterial endocarditis: a review for dentist. Oral Surgery, oral Medicine, Oral Pathology, Baltimore,1985, v. 60, n.2, p. 159-165. 